\title{
Exploring Business Models for MOOCs in Higher Education
}

\section{Elizabeth L. Burd, Shamus P. Smith and Sorel Reisman}

Abstract: Massive Open Online Courses (MOOCs) potentially challenge the traditional dominance of brick and mortar institutions as providers of quality higher education. The benefits for students include reduced education costs and global access to exclusive institution courses and instructors. However, the benefits for institutions are less clear as there is a financial overhead required to develop and deliver content that is suitable for mass student consumption. In this article we examine the opportunities that MOOCs provide and identify several different business model challenges for offering MOOCs.

Keywords Massive open online course, Open education, Business model, MOOC

Massive Open Online Courses (MOOCs) are online educational materials delivered via an electronic medium and offered freely and openly to learners. The difference between MOOCs and traditional online courses is that online courses have students registered to a particular institution of study whereas MOOCs are available and open to anyone, hence potentially appealing to massive numbers of students. This means they are often typically under open

Elizabeth L. Burd is Pro-Vice Chancellor Learning \& Teaching and Professor at The University of Newcastle (Australia). She received her B.Ed. (Hons) from Worcester College of Higher Education (UK), M.Sc. and D.Phil. from The University of York (UK) and Ph.D. from Durham University (UK). Her research is focused on furthering Computing pedagogy and technology enhanced learning. Email contact: Liz.Burd@newcastle.edu.au

Shamus P. Smith is a Senior Lecturer in Computer Science at The University of Newcastle (Australia). He received his B.Sc. (Hons) and Ph.D. from Massey University (New Zealand). His research is focused on virtual environments, human-computer interaction and technology enhanced learning. Email contact:

Shamus.Smith@newcastle.edu.au

Sorel Reisman is Professor of Information Systems at California State University, Fullerton, and Managing Director of the MERLOT project (www.merlot.org) at California State University Office of the Chancellor. He received his B.A.Sc., Dip. D.P., M.A. and Ph.D. from the University of Toronto. He was 2011 President of the IEEE Computer Society, is Editor-in-Chief of the IEEE eLearning Library, and has research interests in open education resources and education management. Email contact: sreisman@computer.org

Cite as: Burd, E.L., Smith, S.P. \& Reisman, S. Exploring Business Models for MOOCs in Higher Education. Innov High Educ 40, 37-49 (2015). https://doi.org/10.1007/s10755-014-9297-0 
access agreements and therefore could conceivably be incorporated into another institution's instructional portfolio without necessarily infringing copyright.

Unlike typical courses and programs of study in higher education, MOOCs commonly have no application process. There is no requirement for a learner to apply for registration in a MOOC and therefore no possibility of rejection. The learner is free to decide if they meet the stated prior learning requirements and to ignore them if they do not, and in some forms of MOOCs the learner may easily ignore the structure of the learning tasks recommended by the course designer. Therefore, one might perceive MOOCs as free from the institutional constraints that a traditional schooling system imposes.

The promise of a MOOC is that it is assumed to allow free access to high quality education and leading research. Yuan and Powell (2013) observed that "the development of MOOCs is rooted within the ideals of openness in education, that knowledge should be shared freely, and the desire to learn should be met without demographic, economic, and geographical constraints" (p. 6). The current reasons for higher education institutions to offer MOOCs have been identified as access, experimentation, and brand extension (EDUCAUSE, 2012). However, institutions may fear the stated promise of MOOCs because they could potentially impact enrolment at traditional institutions and ultimately reshape the higher education market if they are developed to the point whereby learners can complete degrees and gain qualifications.

Politically, in Australia and the U.S., MOOCs are seen as potentially driving down the cost of education and disrupting current education business models. Gallagher and Garrett (2013) highlighted how proponents of MOOCs envision a world in which "anyone anywhere anytime can access high quality higher education at no or low cost" (p. 8) and "universities upend their place-based business model by moving all instruction and assessment online, dramatically cutting costs, passing on big savings to students" (p. 38). Thus, politicians may see MOOCs 
as an opportunity to address budget constraints and lower the cost of education by enabling inexpensive, low-risk experimentation (Carey, 2013). However, while politically MOOCs are celebrated for the potential of reducing costs, in a regulatory sense they could pose challenges to higher education institutions. For instance, if MOOCs were to replace for-credit course offerings, then the institution could be embarking on what is in effect a third party collaborative arrangement with the MOOC provider. However, the quality of the learning process would not be wholly under that institution's control because of MOOCs predominant reliance on peer tutoring and feedback.

In the United Kingdom (UK) a study commissioned by the Joint Information Systems Committee (JISC) offered a note of caution to the MOOC phenomenon and the impact it could have on higher education (Yuan \& Powell, 2013). The JISC warned that the newness of the MOOC phenomenon "opens up the risk that decisions will be made in a fragmented way by different unconnected groups without a deep understanding or clear analysis of MOOCs and other potential education delivery models" (p. 5). They recommended that higher education institutions "will need to develop a comprehensive strategy to respond to the opportunities and threats posed by MOOCs and other forms of openness in higher education" (Yuan \& Powell, p. 5). Specifically their concerns focused on the number of institutions generating content for free and then not using this content within their own institution. Thus "there is a challenge in finding a viable model that allows for sustainability of MOOC provision" (Yuan \& Powell, p. $4)$.

In this article we explore MOOCs in general and examine current MOOC providers in particular. We identify challenges to MOOC development and use and present several business models. Finally we review the revenue potential of MOOCs in the context of key MOOC providers and discuss how this might impact higher education institutions in the future. 


\section{An Overview of Massive Open Online Courses}

A Massive Open Online Course (MOOC) is an online educational resource aimed at large-scale interactive participation via the Internet. MOOCs deliver educational content through videos, voice clips, written materials, and problems for students to work. Some of the more advanced MOOCs provide opportunities for interactive experiences through user forums. MOOCs are a form of online distance learning but typically do not offer support structures other than through course peers. Thus assessment is often restricted to automated marking unless additional fee structures are incorporated. Institutions tend to re-purpose existing courses for external consumption. Two recent reviews of the MOOC literature can be found in Haggard (2013) and Yuan and Powell (2013).

Different ideologies have driven MOOCs in two distinct pedagogical directions:

- The connectivist MOOCs (cMOOC) which are based on a connectivism theory of learning networks that are developed informally, and

- The content-based MOOCs (xMOOCs) which follow a more behaviorist approach. cMOOCs promote collaborative learning, are typically run on open source learning platforms, and are led by academics as part of their institution activity. Their pedagogical model is peer-based learning (Haggard, 2013). However, xMOOCs are associated with typical pedagogical models in which content is delivered by paced sessions of video and examined by online testing.

Two of the key international providers of MOOCs are edX (http://www.edx.org) and Coursera (http://www.coursera.org). edX is a non-profit corporation based in Cambridge, Massachusetts and is governed by MIT and Harvard. Coursera is a for-profit educational technology company and is based in Mountain View, California. Both of these providers stage the learning process for the majority of their courses in a synchronous, scheduled fashion, starting delivery at a specific date and time and releasing content at a set rate. Other 
organisations offering MOOC content include the Open University (UK) (http://www.open.ac.uk) and Udacity (http://www.udacity.com). Unlike other key providers, Udacity's typical pedagogy is a student-led model by which the student defines the pace of learning. Courses can therefore be accessed at all times rather than having to wait for the course to start. However, this does reduce opportunities to create cohorts of learners and the viability of using collaborative tools such as wiki as users are at different stages of their learning.

Some MOOC providers restrict their collaboration, or partnerships, to specific countries or types of institutions. For instance, Coursera includes within their contractual language a statement to the effect that it offers preference to those institutions within the Association of American Universities, or only to institutions outside North America that are ranked within a country's top five universities (Rivard, 2013a).

While registration rates are very high, the number of students who successfully complete MOOCs is low. Attis, Koproske and Miller (2012) reported that, when a combination of a celebrity professor from Stanford (Udacity CEO Sebastian Thrun), a cutting-edge corporation (Google), and a popular subject in artificial intelligence (the driverless car) came together, they brought the virtual classroom to a scale few could imagine. This course was able to attract 160,000 students. However, the course was completed by only 28,000 of those students who registered, i.e. a $17.5 \%$ completion rate. This outcome, however, was considerably more positive than many MOOCs achieve, where completion can be as low as 5\% (Bruff, 2013; EDUCAUSE, 2012; Gallagher \& Garrett, 2013). A contributing factor in the Stanford experiment was that Sebastian Thrun solicited résumés from the top students and promised "to get the best ones into the right hands at tech companies, including Google" (Leckart, 2012). 


\section{MOOC Business Models}

There is considerable discussion in the media regarding business models that will support the sustainability of MOOCs (Attis, Koproske, \& Miller, 2012; EvoLLLution NewsWire, 2013; Kolowich, 2012a; Young, 2013). At present, such models focus only on the sustainability of MOOCs as individual courses. Most MOOCs are focused at introductory undergraduate level or are typically used within a public lecture series. Currently, three of the most frequently cited business motivations for offering MOOCs include (a) charging for certificates, (b) linking students with potential employers, and (c) charging for supplementary services. A specific analysis by Moody's Investors Service (Kedem \& Puchalla, 2012, p. 1) identified the following opportunities:

- New revenue opportunities through fees for certificates, courses, degrees, licensing, or advertisement.

- Improved operating efficiencies due to the lower cost of course delivery on a per student basis.

- Heightened global brand recognition and the removal of geographic campus-based barriers to attracting students and faculty.

- An enhanced and protected core residential campus experience for students at traditional not-for-profit and public universities. (In this context, a MOOC is used as part of a blended learning approach and provides additional support for on-campus students.)

- The longer-term potential to create new networks of much greater scale across the sector, allowing more colleges and universities to specialise while also reducing operating costs.

- New competitive pressure on for-profit and some not-for-profit institutions that fail to align with emerging high-reputation networks or find a viable, independent niche. 


\section{Linking Students to Employers}

As indicated by the "Stanford Education Experiment" (Leckart, 2012), there is a potential business model around course providers' being able to recommend successful students' résumés to potential employers. The feasibility of this approach will likely vary across institutions and MOOC providers and depend on existing partnerships with employers, or by the creation of new partnerships initiated through the production of high profile MOOCs. Such arrangements will also be dependent on the employment sector. David Stavens, the chief operating officer at Udacity (May 2012-April 2013), observed that in Silicon Valley, head-hunters often get paid finder's fees equivalent to $20 \%$ of a software engineer's starting salary; as a potential revenue opportunity, this could mean around $\$ 15,000$ per match (Kolowich, 2012a). However, there could be considerable fluctuation in this revenue stream. Although, hiring costs generally increase with skill requirements for job applicants, they do depend on macroeconomic conditions (Blatter, Muehlemann, \& Schenker, 2011).

\section{Revenue Opportunities by Offering Certificates}

Many MOOC providers have taken up opportunities to charge for certificates. While such an approach may seem highly advantageous, due to low completion rates (Sandeen, 2013) it typically does not result in significant returns. Although few organisations offer formal course credit for MOOCs, some are exploring such opportunities. Companies such as Pearson (http://www.pearsoned.com) have recognised possible assessment revenue opportunities and are providing examination centres to support secure assessment processes.

Cost and revenue agreements are typically made between individual institutions and the MOOC provider, and so it is difficult to obtain precise details regarding these agreements. However, some have been made public through Freedom of Information requests, typically from the press, regarding the procurement strategies adopted prior to the signing of such 
agreements. Using this information, an assessment has been conducted to identify the number of student registrations that would be required for certificate revenue to equal MOOC development and operation costs, i.e., the break-even point, for the two major MOOC providers (see Cost and Revenue Opportunities below). The results show that in the best case scenario, i.e. charging at the top end for certificates and reducing production costs to a minimum, a MOOC must register over 100,000 students to make a profit from the selling of “Certificates of Achievement," but at present typical MOOC registration numbers are considerably below this figure with an average enrolment per MOOC of around 50,000 students (Colman, 2013; Jordan, n.d.).

Blended or Replacement for Face-to-face Courses within the Institution

A few intuitions have created MOOCs for both public consumption and also for credit for students already registered within an academic program. Attis, Koproske and Miller (2012) observed that "early arrangements at the University of Washington and the University of Maryland University College require students seeking credit for MOOC completion to enrol, pay full tuition, and complete extra assignments in order to prove competency" (p. 13). This can decrease waiting time for high profile courses and allow students to complete their programs more quickly. It is also seen as a way of decreasing the cost of a state education. However, Rivard (2013b) reported that one institution, San José State University, announced in July 2013 that they were going to review this practice due to high failure rates. In comparison to the number of students in traditional classes who passed, greater than $74 \%$, no more than $51 \%$ of Udacity students passed any of three MOOC courses. San José State University has since started working with edX using their MOOCs in the context of a blended course to support traditional face-to-face teaching (Rivard, 2013b).

San José State University recently published a preliminary report (Firmin, Schiorring, 
Whitmer, Willett, \& Sujitparapitaya, 2013) on their collaboration with Udacity, where they note that "regression analysis did not find a positive relationship between use of online support and positive outcomes" (p. ii). However, they did identify several factors that complicated students' ability to use the support services fully, including "their limited online experience, their lack of awareness that these services were available and the difficulties they experienced interacting with some aspects of the online platform" (Firmin et al., p. ii). In responding to these issues, MOOC providers are evolving their delivery platforms. For example Udacity is claiming a $83 \%$ completion rate its "MOOC 2.0" that modifies their free and student-led model to one that (a) charges a small fee; (b) offers a certificate of value (in this case, for academic credit); and (c) gives students guidance and services, including access to a help line (Hyman, 2013).

Some institutions within the U.S., namely those in the Online Consortium of Independent Colleges and Universities (http://www.ocicu.org), are using the blended/replacement model to support course sharing (Attis, Koproske, \& Miller, 2012). Courses are broadcast as a teleconference, and remote students participate in real time. Such an approach is useful for topics where scarce specialist knowledge is required or where there are only small numbers of students across the institutions within the consortium. In the UK such offerings are often arranged for non-credit courses and other postgraduate seminar arrangements. While such approaches are now being marketed as a MOOC style arrangement, its construct is more closely tied to a collaborative agreement because its "openness" is limited to those within that consortium. Nevertheless, expanding such a model to include course credit is not without its pitfalls. In addition to regulating the quality of externally delivered content, there is the need to identify where individual MOOC courses into an institution's degree program (EDUCAUSE, 2012). Gallagher and Garrett (2013) observed that accrediting MOOC content 
towards degrees would "be a massive step, requiring at minimum market acceptance of the new credentials" (p. 14).

Revenue by Attracting Future Students

Another and less well publicised MOOC business model is dependent on "big data" or data analytics that can provide indirect financial advantage. There is a growing realisation that data concerning user activity with online services enable a better understanding of the strengths and weaknesses of such "e-services" and the value they can generate (Loukis, Pazalos, \& Salagara, 2012). Also, the utilisation of data analytics can improve the accuracy of decision making, for instance by identifying markets in which to target specific advertising campaigns. For postgraduate ${ }^{2}$ programs in particular, there is perceived to be a significant value in gaining access to the contact details of students who might be interested in further study. However, it is currently unclear who owns this data; but in most cases it is likely to be the infrastructure provider and not the course provider. Further complications include the ethical issues of conducting and using such forms of data analyses.

The value of this data also depends on the likelihood of the user community taking up any services offered. A number of financial models for MOOC providers assume that the data from student registrations could be used by institutions to attract new students. Thus a number of studies have recently sought to identify the age and experience of those registered. The studies note that such business assumptions are not as strong as one might assume. For instance, Sandeen (2013) examined registrations on Coursera MOOCs and concluded that over $80 \%$ of participants had already earned one or more degrees and were not necessarily seeking additional ones. Kolowich (2012b) documented the profile of MOOC users who completed edX's first course, a virtual lab-based electrical engineering course called "Circuits \& Electronics". He noted that $50 \%$ of participants were aged 26 or over, $45 \%$ were aged from 18

\footnotetext{
${ }^{2}$ In North American usage, this term is to be understood as "graduate."
} 
to 25 , and $5 \%$ were aged 17 or under. Consequently, the market niche is most likely for postgraduates, not undergraduates. Further, a survey conducted by Duke University (Belanger \& Thornton, 2013) on Duke’s first MOOC, “Bioelectricity: A Quantitative Approach", delivered on the Coursera platform found that fun and enjoyment were selected as important reasons for enrolling by a large majority of students. Thus claims of financial benefit from MOOC registrations need to factor in a proportion of recreational participants who are unlikely to contribute to any future revenue generation.

A small number of institutions (including MIT and Harvard) also claimed to be using such data to improve the quality of the learning experience in their more traditional forms of learning (Yuan \& Powell, 2013). In this context they noted MOOCs as an opportunity to experiment in a low risk environment (Carey, 2013).

Increases Awareness of an Institution's Brand

With high quality design and appropriate content MOOCs have the potential to increase the awareness of an institution's brand significantly, both nationally and internationally (EDUCAUSE, 2012). Specifically, MOOCs can offer a university the opportunity to:

- Create exempla of high quality online student experiences that are usually only available through formal online / distance education routes,

- Increase in recognition as a leader in public education,

- Promote awareness of the institution's research contributions to a wider range of individuals.

For the research community the potential gain is likely to be increased awareness of research accomplishments through increased citation and a potential increase in the number of graduate student applicants.

Challenges to MOOC Providers 
The success of such business models depends on the engagement of a large number of learners and getting them to support others through their learning. However, in order to establish this strong user base for a potential MOOC, it is important to:

- Identify a niche area. It is important to find a content area that is not already populated, or at least not overly dominated, by others.

- Agree to quality indicators. It is important to ensure that the reputation of the institution or entity offering the MOOC is enhanced by the product. Thus an institution must confirm that there are defining policies and practices in place to control the quality of all products produced.

- Deal with attrition. MOOCs have extremely high attrition, typically between $85-95 \%$ (Bruff, 2013; EDUCAUSE, 2012; Gallagher \& Garrett, 2013; Sandeen, 2013), which is similar to other voluntary online training environments (Sitzmann, 2011). Morris (2013) observed that "the high dropout rate is attributed to both the educational environment and the administrative structure, i.e. mind boggling numbers, open enrolment, no investment to enrol, and the lack of academic credit for successful completion" (p. 251). Other contributing factors include inadequate preparation and immaturity of the learner. If learning activities rely on group activity, then disengaged peers are a detriment to the learning of others. Strategies must be in place to ensure that group work is viable.

- Define realistic (and cost effective) support and guidance procedures. Typically, the only form of help offered in most MOOCs is peer assistance. Thus their design, including their interface, content, and associated pedagogy, should be accessible without the need for extra support. While collaborative discussion tools are useful to support group-based activity and assessment, such activities need an assigned moderator (Asterhan, 2011) to ensure that the reputation of the institution is not negatively impacted. 
In addition to the above, there is the challenge of differentiating MOOCs from existing credit courses. If a MOOC appears to offer the same learning experience as existing for-credit courses, registered students may become concerned about the value their program offers.

\section{Cost and Revenue Opportunities}

At present, financial models are more commonly available for MOOCs through edX (http://www.edx.org) and through Coursera (http://www.coursera.org). In our analysis we consider the impact of the financial model only. However, since the availability of a MOOC acts as publicity for an institution, this cost benefit analysis is a simplistic assessment. Nevertheless, the following analysis shows the impact of certain types of decision-making (for instance, choice of provider or certificate cost) and shows the typical number of learners that would have to register before a MOOC would break even. Some providers may also allow sharing of other revenue, such as for advertising. However, no data are publicly available from such agreements, so this potential income is also excluded from the analysis.

We offer a set of assumptions regarding the financial modelling of break-even points. In each case the assumptions used to generate costs have been reported in academic experience reports or other media outlets.

Assumption 1: Modelling the Learner Community

On average, around 50,000 students register for a MOOC (Colman, 2013; Jordan, n.d.) and between 5-15\% of students complete the MOOC (Bruff, 2013; Sandeen, 2013); 2\% of the numbers of students examined earned a basic certificate of course completion, and $0.17 \%$ earned a certificate of higher performance, i.e. distinction (Yuan \& Powell, 2013).

\section{Assumption 2: Charging for Certificates}

Typically, certificates are charged to the student at $\$ 20-\$ 50$ (Lewin, 2013); and sometimes higher charges are made, especially when the certificates are authenticated through an examination centre. Therefore, assuming 50,000 students registered for a specific MOOC, if 
between $0.17 \%$ and $2 \%$ of eligible students claim certificates, this equates to $85-1000$ students. Thus, the predicted gross revenue from issuing certificates is $\$ 1,700-\$ 50,000$. (Assumptions: range 85 students @ \$20 per certificate to 1000 students at $\$ 50$ per certificate).

\section{Assumption 3: Costs of Producing a MOOC}

Current estimates of what it costs to develop a MOOC vary enormously. Estimates can include the initial development of material (considered here) and the ongoing running costs (see Assumption 4 below). Gallagher and Garett (2013, p. 27) noted that MOOCs can cost from as little as a couple of hundred dollars for "technology combining voiceovers and PowerPoint slides" to $\$ 25,000$ with "only direct costs and without high production values" to up to half a million dollars including more elaborate production values and likely including all development, teaching, and administration costs. Here we consider the costs to initially produce a MOOC, and we base our calculations on the assumption that it requires around 100 hours of work to generate the content (Kolowich, 2013b), at an average cost of between $\$ 15,000$ to $\$ 50,000$ (Colman, 2013). It should also be noted that often, due to intellectual property issues, proprietary content such as graphics from books cannot be used in a MOOC and thus need to be regenerated in a suitable format. Thus, the costs considered in this analysis are likely to be considerably lower than actual costs.

\section{Assumption 4: Costs of Running a MOOC}

For the larger MOOCs some academics have reported blogs and wiki requiring around 300 hours to moderate over a period of about 10 weeks. Justifications for this estimate include one report that identified that over 600 pages of comments could be generated during the operational period of a MOOC (Edwards, 2012). Web blogs and other media outlets indicate that some staff in the U.S. are being awarded a stipend of $\$ 10,000$ per iteration of a MOOC (Davidson, 2013). 
Therefore, taking into account (a) the financial estimates for Assumption 3, (b) the production of a single MOOC and (c) the operation costs for an iteration of that MOOC, the costs for running for a single MOOC are within the range of $\$ 25,000-\$ 60,000(\$ 15 \mathrm{~K}$ production $+\$ 10 \mathrm{~K}$ operation costs versus $\$ 50 \mathrm{~K}$ production and $\$ 10 \mathrm{~K}$ operation costs).

Assumption 5: Assessing the Costs of International Partnership

Assumption 5a: Partnership with edX edX offers two types of partnership opportunities (Kolowich, 2013a) which are:

- edX University Self-service Model: For this partnership edX requires the first $\$ 50,000$ for the first iteration of the course (see Equation 1) and $\$ 10,000$ for each future iteration (see Equation 2). After reaching the initial reserve, edX and the institution offering the MOOC receive a 50/50 split of revenue. The institution pays all the MOOC developmental and operation costs.

Initial iteration revenue $=($ Revenue $-\$ 50,000) / 2-$ Development and Operation costs $(1)$

Future iteration revenue $=($ Revenue $-\$ 10,000) / 2-$ Operation cost

- edX Supported Model: For this partnership edX requires an up-front payment of $\$ 250,000$ per course (see Equation 3) and \$50,000 per repeat course iteration (see Equation 4). edX then pays the developmental and operation costs and the institution gets $70 \%$ of revenue from the MOOC (Young, 2013).

Initial iteration revenue $=($ Revenue $* 0.70)-\$ 250,000$

Future iteration revenue $=($ Revenue $* 0.70)-\$ 50,000$

Assumption 5b: Partnership with Coursera For this partnership Coursera requires the institution offering the MOOC to pay all the developmental and operation costs. Coursera provides an Application Programming Interface (API) to enable the institution to connect 
with their delivery platform and hosting services to stream content to students. Coursera then returns between $6-15 \%$ revenue, namely $6 \%$ for a course with a three-month lifespan, $9 \%$ for a course with a 12 -month lifespan (see Equation 5), $12 \%$ for a course with a 24-month lifespan (see Equation 6) and 15\% for a course with a 36-month lifespan (see Equation 7) (EvoLLLution NewsWire, 2013; Young, 2012a; Young, 2012b).

12-month lifespan revenue $=($ Revenue $* 0.09)-$ Development and Operation costs

24-month lifespan revenue $=($ Revenue $* 0.12)-$ Development and Operation costs

36-month lifespan revenue $=($ Revenue $* 0.15)-$ Development and Operation costs

Assumption 6: Predicting Learner Numbers for Break-Even Revenue

The calculations in Table 1 show the total number of students that would need to register for the first, second or third iteration of a MOOC in order to reach break-even points. Our revenue and cost calculations are made on the following basis:

- Highest revenue, lowest cost (HR/LC) assuming $\$ 50$ per certificate, $2 \%$ completion against \$15K development and \$10K operation costs.

- Highest revenue, highest cost $(\mathrm{HR} / \mathrm{HC})$ assuming $\$ 50$ per certificate, $2 \%$ completion against \$50K development and \$10K operation costs.

- Lowest revenue, lowest cost (LR/LC) assuming \$20 per certificate, $0.17 \%$ completion against $\$ 15 \mathrm{~K}$ development and $\$ 10 \mathrm{~K}$ operation costs.

- Lowest revenue, highest cost (LR/HC) assuming \$20 per certificate, $0.17 \%$ completion against $\$ 50 \mathrm{~K}$ development and $\$ 10 \mathrm{~K}$ operation costs. 


\section{Table 1}

Total Number of Students Required to Reach Break-even Point for One, Two, and Three MOOC Iterations across Three MOOC Provider Models

\begin{tabular}{lllll}
\hline $\begin{array}{l}\text { MOOC Provider } \\
\text { (iteration) }\end{array}$ & $\begin{array}{l}\text { High revenue / } \\
\text { low cost }\end{array}$ & $\begin{array}{l}\text { High revenue / } \\
\text { high cost }\end{array}$ & $\begin{array}{l}\text { Low revenue / } \\
\text { low cost }\end{array}$ & $\begin{array}{l}\text { Low revenue / } \\
\text { high cost }\end{array}$ \\
\hline & & & & \\
edX self-service(1) & 100,000 & 170,000 & $2,940,000$ & $5,000,000$ \\
edX supported(1) & 357,000 & 357,000 & $10,500,000$ & $10,500,000$ \\
Coursera(1) & 278,000 & 668,000 & $8,200,000$ & $19,610,000$ \\
& & & & \\
edX self-service(2) & 130,000 & 200,000 & $3,820,000$ & $5,880,000$ \\
edX supported(2) & 429,000 & 429,000 & $12,608,000$ & $12,608,000$ \\
Coursera(2) & 292,000 & 584,000 & $8,580,000$ & $17,160,000$ \\
& & & & \\
edX self-service(3) & 160,000 & 230,000 & $4,710,000$ & $6,765,000$ \\
edX supported(3) & 500,000 & 500,000 & $14,706,000$ & $14,706,000$ \\
Coursera(3) & 300,000 & 534,000 & $8,820,000$ & $15,690,000$ \\
& & & & \\
\hline
\end{tabular}

Note: Break-even numbers calculated to the nearest 1000 students.

The calculations in Table 1 also assume the following, which are unlikely to hold:

- That operation costs remain static regardless of the number of students registered (for example the Higher Education Price Index (2013) has ranged from 5\% in 2008 to $0.9 \%$ in 2010 to $1.6 \%$ in 2013$)$;

- That the operation costs are fixed at $\$ 10,000$ per course;

- That the total production costs, including staffing and material production are a maximum of $\$ 50,000$.

It is interesting to consider the disparity of those costs and those of the supported model operated by edX, with institutions contributing an up-front payment of $\$ 250,000$ per course and $\$ 50,000$ per course iteration and edX covering the developmental and operation costs. 


\section{Considering Future MOOCs at an Institutional Level}

If an institution is to get benefit from the development of a MOOC, then it must:

- Identify a discipline area that has broad appeal and is not currently offered by another provider, to ensure that sufficient students join the course;

- Design content and assessments appropriate to those learners most likely to be interested in the content;

- Ensure that the product is of high quality and has sufficient scaffolding and support structures to ensure that students engage and successfully complete the course;

- Have an international appeal.

In light of the cost/revenue balance highlighted above, institutions must recognise that such strategies are unlikely to result in direct financial reward if they wish to offer MOOCs or expand MOOC-type activity. Rather, the value to the institution is likely to be in terms of enhanced institutional awareness in home and global markets. However, to achieve these aims the conditions stated above still need to hold true. Thus, two potential opportunities for exploration are the use of MOOCs as pre-admission tools to prepare students for admission and to enhance an institution's brand recognition:

- bridgeMOOC: The aim here is to support skills development, for example of literacy and numeracy, for students prior to entering the institution. This form of MOOC could be used to help prepare students entering an institution for a specific course or program of study, but could additionally be promoted "openly" as a means to prepare students for a university education (Firmin et al,. 2013). This could raise the profile of the institution and prove an important support tool for schools and adult education centres.

- brandMOOC: These MOOCs promote awareness of and could increase applications to a postgraduate program in which an institution has research excellence. By focusing on an 
area of research excellence, an institution could offer a MOOC, differentiated from those available elsewhere. Furthermore, since research shows that the majority of students using MOOCs already have, or are presently studying, for a higher education degree, this approach is more likely to satisfy the needs of the audience. Also students who successfully complete a MOOC could be targeted to receive information about associated graduate programs.

These recommendations are made in consideration of the potential audience/market that has an interest in MOOCs (i.e. older students and those who have already attained, or will soon complete an undergraduate level qualification, and those in high schools).

\section{Discussion and Conclusions}

The evolution of MOOCs is leading to more players in the market as higher education institutions and private organisations seek to take advantage of these innovations in online learning. If, in the future, MOOCs can be developed to the point whereby learners can complete full undergraduate degrees and gain qualifications, they may impact enrolment at traditional institutions and could contribute to the reshaping of the higher education market. However, the reality is that fully online degree programs are already here. So the question is, "Does higher education want to discount degrees to the extent of charging only for certificates and reducing the opportunities for staff and student engagement to a minimum?"

While institutions may fear the impact MOOCs could have on higher education in general, in reality this fear is unfounded. Many of the institutions that offer MOOCs gain their reputation from the exclusivity of their campus-based student cohort. Consequently, it is unlikely that such institutions would want to grant millions of students a full undergraduate degree (thus diluting their brand), nor would they want to disrupt their existing business models by offering certification at such a discounted rate. 
Furthermore, it is important to remember the value of a face-to-face education and the opportunities that studying in a community of learners and researchers brings. Therefore institutions need to think clearly about the evolution of face-to-face forms of education, and students need to think about what it means to be part of a learning culture in an environment influenced by research. Hence, enhancing staff-to-students and peer-to-peer interaction needs to be a primary consideration of any future planning activity.

Where MOOCs are more of a direct threat is to "traditional," online education. As more institutions gain confidence in computerised education and assessment and other organisations present mechanisms to support the international authentication of examination sessions, then institutions with a focus on online provision may face significant challenges to their extant business models. For instance, while high profile institutions are unlikely to create full undergraduate degree MOOCs, they are likely to offer certificates of completion on a course-by-course basis. Institutions or private providers who do not have the same constraints imposed by external accreditation bodies could, without reproach, trade these certificates for course credit. Thus, their online programs could be offered at a considerably lower price; and, with a high proportion of accredited prior learning, completion times for full qualifications could be vastly reduced. In such cases the quality of an institution's educational provision and academic reputation will continue to be of paramount importance for long-term sustainability.

To survive such challenges institutions may need to implement agile course development and approval processes that create resources that can be purposed and repurposed for both online and campus-based education. As the "Digital Native" generation moves towards a graduate education, institutions will have to supplement existing learning materials with more interactive, multimedia content. Institutions must move away from thinking about the prized 50 minute lecture and the importance of the individual delivering it and think of courses as being a collection of learning resources, with staff as facilitators of learning. The importance 
of active forms of learning must be emphasised, with opportunities for practice and experimentation critical for the assessment of learning outcomes at all qualification levels. MOOCs and other forms of open educational content provide institutions opportunities for brand extension, but these technologies also pose risks to current business models. To address such challenges it is important that institutions be selective about the channels they use and the content that they make freely available.

\section{References}

Asterhan, C. S. C. (2011). Assessing e-moderation behavior from synchronous discussion protocols with a multi-dimensional methodology. Computers in Human Behavior, 27, 449458.

Attis, D., Koproske, C., \& Miller, C. (2012). Understanding the MOOC trend: The adoption and impact of massive open online courses. Washington, DC: The Education Advisory Board. Retrieved from http://www.eab.com

Belanger, Y., \& Thornton, J. (2013). Bioelectricity: A quantitative approach. Duke University's first MOOC. Durham, NC: Duke University. Retrieved from http://hdl.handle.net/10161/6216

Blatter, M., Muehlemann, S., \& Schenker, S. (2012). The costs of hiring skilled workers. European Economic Review, 56, 20-35.

Bruff, D. (2013, February 19). Online learning ecosystems: What to make of MOOC dropout rates? [Blog message]. Retrieved from http://derekbruff.org

Carey, K. (2013, February 13). Obama, Rubio agree on one thing: Technology could fix the Higher Ed mess. Slate. Retrieved from http://www.slate.com

Colman, D. (2013, April 2). The big problem for MOOCs visualized. Open Culture. Retrieved from http://www.openculture.com 
Davidson, C. (2013, November 6). Clearing up some myths about MOOCs [Blog message]. Retrieved from Humanities, Arts, Science and Technology Alliance and Collaboratory (HASTAC) website http://www.hastac.org

EDUCAUSE. (2012, December 20). What campus leaders need to know about MOOCs: an EDUCAUSE executive briefing. Louisville, CO: EDUCAUSE Publications. Retrieved from http://www.educause.edu

Edwards, C. (2012, August). MOOC's: An analysis for BCIT. British Columbia, Canada: British Columbia Institute of Technology. Retrieved from http://landing.athabascau.ca EvoLLLution NewsWire. (2013). Finally, a business model for MOOCs. EvoLLLution. Retrieved from http://www.evolllution.com

Firmin, R., Schiorring, E., Whitmer, J., Willett, T., \& Sujitparapitaya, S. (2013, September). Preliminary Summary: SJSU+Augmented Online Learning Environment: Pilot Project. San Jose, CA: Research and Planning Group for California Community Colleges. Retrieved from http://www.sjsu.edu

Gallagher, S., \& Garrett, G. (2013, July 31). Disruptive education: Technology Enabled Universities. Sydney, Australia: United States Studies Centre, University of Sydney. Retrieved from http://ussc.edu.au

Haggard, S. (2013). The maturing of the MOOC (BIS Research paper number 130). London, England: Department for Business, Innovation and Skills. Retrieved from http://www.gov.uk

Higher Education Price Index (2012). Retrieved from the Commonfund Institute website: http://www.commonfund.org

Hyman, P. (2013, October 22). MOOCs evolve; Version 2.0 aims to retain more students. Communications of the ACM. Retrieved from http://cacm.acm.org 
Jordan, K. (n.d.). MOOC Completion Rates: The Data [Table]. Retrieved from http://www.katyjordan.com

Kedem, K., \& Puchalla, J. E. (2012). Shifting ground: Technology begins to alter centuries-old business model for universities. (Report Number 144483), New York, NY: Moody’s Investors Service. Retrieved from http://www.moodys.com

Kolowich, S., (2012a, June 11). How will MOOCs make money? Inside Higher Ed. Retrieved from http://www.insidehighered.com

Kolowich, S. (2012b, September 12). The MOOC Survivors. Inside Higher Ed. Retrieved from http://www.insidehighered.com/

Kolowich, S., (2013a, February 21). How EdX plans to earn, and share, revenue from its free online courses. The Chronicle of Higher Education, Retrieved from http://www.chronicle.com

Kolowich, S., (2013b, March 24). The Professors Who Make the MOOCs. The Chronicle of Higher Education. Retrieved from http://www.chronicle.com

Leckart, S., (2012, March 20). The Stanford education experiment could change higher learning forever. Wired. Retrieved from http://www.wired.com

Lewin, T., (2013, January 6). Students rush to web classes, but profits may be much later. The New York Times. Retrieved from http://www.nytimes.com

Loukis, E., Pazalos, K., \& Salagara, A. (2012) Transforming e-services evaluation data into business analytics using value models. Electronic Commerce Research and Applications, $11,129-141$.

Morris, L. V., (2013). MOOCs, emerging technologies, and quality. Innovative Higher Education, 38, 251-252.

Rivard, R., (2013a, March 22). Coursera’s contractual elitism. Inside Higher Ed. Retrieved from http://www.insidehighered.com 
Rivard, R., (2013b, July 18). Udacity project on “pause”. Inside Higher Ed. Retrieved from http://www.insidehighered.com

Sandeen, C., (2013, July 18). From hype to nuanced promise: American higher education and the MOOC 3.0 era. The Huffington Post. Retrieved from http://www.huffingtonpost.com

Sitzmann, T., (2012). A theoretical model and analysis of the effect of self-regulation on attrition from voluntary online training, Learning and Individual Differences 22, 46-54.

Young, J. R., (2012a, July 19). Inside the Coursera contract: How an upstart company might profit from free courses. The Chronicle of Higher Education. Retrieved from http://www.chronicle.com

Young, J. R., (2012b, July 19). The U. of Michigan's contract with Coursera. The Chronicle of Higher Education. Retrieved from http://www.chronicle.com

Young, J. R., (2013, February 21). Revenue-sharing models between edX and university partners. The Chronicle of Higher Education. Retrieved from http://www.chronicle.com

Yuan, L., \& Powell, S., (2013). MOOCs and open education: Implications for higher education (2013:WP01). Bolton, UK: JISC Centre for Educational Technology \& Interoperability Standards. Retrieved from http://www.cetis.ac.uk 